\title{
Failing to respond to health promotion imperatives could scupper or hamper National Health Insurance efforts
}

As the process of finalising the National Health Insurance (NHI) Act intensifies, there is increasing concern that insufficient emphasis is being placed on addressing the demand side of health with people requiring healthcare, relative to the supply side of provision and funding of care and treatment. Freeman et al. ${ }^{[1]}$ argue that with increasing rates of non-communicable diseases (NCDs), the NHI Fund risks being overwhelmed by increasing numbers of people needing healthcare. They recommend that there must be a greater focus on broadly defined health promotion, which must be integral to the conceptualisation and implementation of NHI. This focus should include funding for health promotion from the NHI Fund and establishing an intersectoral structure to deal with the social determinants of health.

Reducing demand for healthcare is a good idea, but is this feasible and achievable in South Africa (SA)? Given serious social and economic determinants of health in SA such as poverty and unemployment, is it possible to promote health so that fewer people become ill and seek care, and if so, how? And is reducing the need for healthcare sufficiently important to be included in NHI legislation and plans, given the other critical NHI issues?

Unfortunately, there is no consensus in SA regarding precisely what health promotion is and which actions would most effectively reduce healthcare demand. Opinions also vary on the effectiveness of health promotion, compounded by insufficient local research and evidence to guide interventions. For some, health promotion is purely patient education and information on health issues, while others regard it as a critical vehicle for tackling the social, economic and commercial determinants of health. Between these poles there are a range of options, e.g. the Ottawa Charter on Health Promotion ${ }^{[2]}$ and the Shanghai Declaration on Promoting Health in the 2030 Agenda for Sustainable Development. ${ }^{[3]}$ Our definition of health promotion would include regulatory or legislative interventions, say to reduce salt, sugar, tobacco and alcohol use and to promote the consumption of healthier food, to reduce container sizes for malt beer, and to facilitate the creation of safe spaces for people to exercise in all communities.

It is inadequate and not cost-effective to reduce health promotion to health education and information, whether through health practitioner education, providing pamphlets to communities or putting up billboards. ${ }^{[4]}$ The importance of tackling the social and economic determinants of health cannot be underestimated. However, it is unclear what this means in practice and how far health sector policymakers and practitioners should be involved in redressing these issues. The global Commission on the Social Determinants of Health showed that people have dramatically different life chances depending on their country of birth, and that within countries, health and illness follow a social gradient, with the lower the socioeconomic position, the worse the health. ${ }^{[3]}$ They recommend that countries should urgently improve the conditions of daily life and tackle the inequitable distribution of power, money and resources.

Adopting a broad health promotion approach is not a new concept in SA. Perez et al..$^{[5]}$ strongly motivated for developing a Health Promotion and Development Foundation, stating that the emphasis of such a foundation 'would be on reducing the effects of poverty, inequity and unequal development on disease rates and wellbeing. Since SA has numerous social and economic challenges that fundamentally impact on health, how far should health promotion go in attempting to redress social and economic determinants? Poverty, high unemployment, lack of housing, inadequate water supplies, gender inequality and violence, landlessness and many other issues affect population health status. Addressing these issues is a stated priority objective of the SA government, and they must be dealt with because of their own definite and essential importance. However, the impact of addressing them on individual and collective health outcomes cannot be understated or overlooked.

The calls from inter alia the United Nations General Assembly and the World Health Organization (WHO) for a 'whole of government', 'health in all policies' and 'whole of society' approach to health must therefore be strongly supported. ${ }^{[6]}$ Poor health status of indigent and rural people can, for example, be utilised as added motivation for poverty alleviation and rural development programmes, with health becoming an additional reason to reduce poverty or develop rural areas. Moreover, information collected on health can be employed to better understand poverty drivers, and the National Department of Health $(\mathrm{NDoH})$ can advise other government departments such as agriculture, transport, trade and the environment on what may be required from them to impact positively on development and health. Moreover, the shaping of interventions by other sectors should be informed by health needs. For example, if promotion of jobs through energy generation is adopted as part of a poverty alleviation strategy, health advocates should argue that this should be in the renewable sector rather than in coal production, as the latter would result in more illness in the longer term. Similarly, in building human settlements, health experts could contribute by informing the lead department of the health benefits of open spaces and parks, bicycle lanes, disability requirements and ventilation in houses, so that health can be promoted.

While SA has done poorly in many aspects of health promotion recommended in international declarations, for example in building public health policies, strengthening community actions and establishing healthy cities, there have been important, and even worldleading, achievements to promote health. These include regulatory interventions such as taxation of sugar-sweetened beverages; limitations placed on salt in foodstuffs; banning of trans fats; increases in taxation of tobacco products and other control measures in the 1990s; and interventions of non-governmental organisations, for example edutainment initiatives such as Soul City and Soul Buddies. More is needed to address behaviour change, including working in family spaces and across communities, to advocate and mobilise for opportunities to make and sustain healthy changes. These changes must also be supported at a legislative and political level, and to combat initiatives where economic policies adversely shape health behaviour choices and where the interests of commercial operators hold primacy.

The WHO identified five main risk factors as key to reducing and redressing NCDs. All of them involve actions from the $\mathrm{NDoH}$ and also other departments. Improving diet, eliminating tobacco use, reducing harmful use of alcohol, increasing physical activity and redressing air pollution cannot be achieved by the $\mathrm{NDoH}$ alone. Central to a whole of government, whole of society and health in all policies approach is the need for the establishment of a multisectoral structure such as a National Health Commission or a Health Promotion Foundation that can be linked, and should be funded by the NHI Fund. This would support a wide range of evidence-based 
health promotion activities. If treatment supply is dealt with by NHI, but health promotion to reduce the demand for services is neglected or completely separated, this could prove fatal to NHI as healthcare needs and demand for health services swamp the supply side. $\mathrm{NHI}$ is an excellent opportunity to get the neglected area of health promotion to play its rightful place in ensuring better health in SA, and to help make NHI affordable and sustainable.

\section{D H Parry}

Alcohol, Tobacco and Other Drug Research Unit, South African Medical Research Council, Cape Town, South Africa; and Department of Psychiatry, Faculty of Medicine and Health Sciences, Stellenbosch University, Cape Town, South Africa charles.parry@mrc.ac.za

\section{J E Simmonds}

Alcohol, Tobacco and Other Drug Research Unit, South African Medical Research Council, Cape Town, South Africa
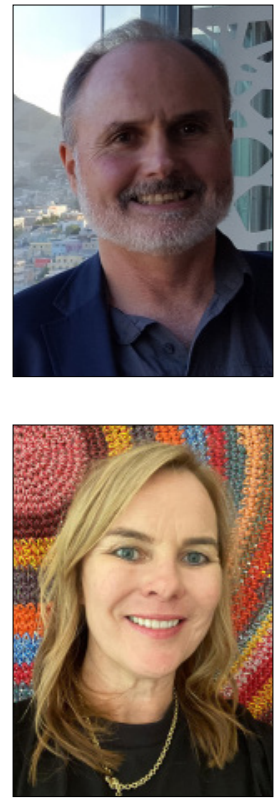

\section{Freeman}

Alcohol, Tobacco and Other Drug Research Unit, South African Medical Research Council, Cape Town, South Africa; and Department of Psychology, Faculty of Arts and Social Sciences, Stellenbosch University, Stellenbosch, South Africa

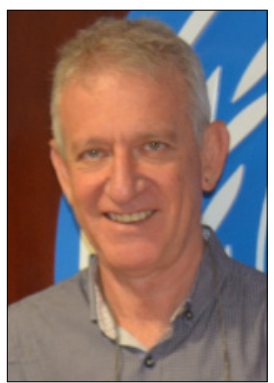

. Freeman M, Simmonds JE, Parry CDH. Health promotion: How government can ensure that the NHI fund has a fighting chance. S Afr Med J 2020;110(3):188-191. https://doi.org/10.7196/ SAMJ.2020.v110i3.14499

2. World Health Organization. The Ottawa Charter for Health Promotion. 21 November 1986. https:// www.who.int/healthpromotion/conferences/previous/ottawa/en/ (accessed 30 January 2020).

3. World Health Organization. Shanghai Declaration on Promoting Health in the 2030 Agenda for . Sustainable Development. https://www.who.int/healthpromotion/conferences/9gchp/shanghai-conference-report/en/ accessed 30 January 2020)

4. World Health Organization. Tackling NCD: 'Best buys' and other recommended interventions for the prevention and control of noncommunicable diseases. Geneva: WHO, 2017. https://www.who. int/ncds/management/best-buys/en/ (accessed 30 January 2020).

5. Perez G, Ayo-Yusuf O, Hofman K, et al. Establishing a Health Promotion and Development Foundation in South Africa. S Afr Med J 2013;103(3):147-149. https://doi.org/10.7196/SAMJ.6281 United Nations General Assembly. Political declaration of the third high-level meeting of the General Assembly on the preverion

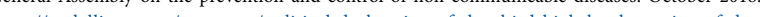
https://ncdalliance.org/resources/political-declaration-of-the-third-high-level-meeting-of-thegeneral-assembly-on-the-prevention-and-control-of-non-communicable-diseases (accessed 30 January 020)

S Afr Med J 2020;110(3):170-171. https://doi.org/10.7196/J.2020.110i3.14497 